\title{
RANDOMIZED COMPARISON OF ULTRASONIC ASPIRATION VERSUS CONVENTIONAL ELECTROCAUTERY FOR DISSECTION OF THE HUMAN INTERNAL THORACIC ARTERY
}

\author{
K. L. Blake, $\mathrm{BSc}^{\mathrm{a}}$ \\ P. A. C. Watt, PDCS ${ }^{a}$ \\ J. M. T. Smith, BSc ${ }^{\mathrm{a}}$ \\ A. C. De Souza, BM, BS, FRCS ${ }^{a}$ \\ T. J. Spyt, MD, FRCS ${ }^{\mathrm{b}}$ \\ H. Thurston, MD, FRCP ${ }^{a}$
}

The most common technique currently employed to harvest the internal thoracic artery for coronary artery bypass grafting is conventional electrocautery. This study compared an alternative method, electrocautery with an ultrasonic aspirator, for harvesting the internal thoracic artery. Patients were randomly assigned to one of six experimental groups (conventional electrocautery, ultrasonic aspirator at settings of $60 \%, 80 \%$, and $100 \%$ power output, and ultrasonic aspirator in 100\% CAVI-Pulse modes 1 and 3). Ring segments of internal thoracic artery were studied in an organ bath. Contraction responses were elicited with $123 \mathrm{mmol} / \mathrm{L}$ potassium physiologic salt solution, KPSS, KPSS solution containing noradrenaline, and a cumulative noradrenaline dose-contraction curve. Relaxation studies were performed with the vasodilators acetylcholine, bradykinin, and sodium nitroprusside. Forty percent of the electrocauterized vessels were traumatized or damaged and failed to respond to contractile stimuli, whereas only $10 \%$ of the vessels in ultrasonic aspirator groups $60 \%, 80 \%$, and $100 \%$ failed to respond. All vessels in the group harvested by ultrasonic aspirator in $100 \%$ CAVI-Pulse mode 1 responded, whereas $20 \%$ of the vessels in the group harvested by ultrasonic aspirator in $100 \%$ CAVI-Pulse mode 3 failed to respond. All settings of electrocautery with an ultrasonic aspirator produced a greater contractile response to KPSS and noradrenaline. Acetylcholine and sodium nitroprusside produced similar relaxations in all groups, but the bradykinin responses were significantly improved in all groups undergoing $100 \%$ electrocautery with an ultrasonic aspirator. These results suggest that $100 \%$ electrocautery with an ultrasonic aspirator, particularly in $100 \%$ CAVI-Pulse mode 1 , resulted in less damage and trauma than conventional electrocautery during harvesting of the internal thoracic artery. (J Thorac Cardiovasc Surg 1996;111:1194-9)
T he internal thoracic artery (ITA) is now used almost universally for coronary artery bypass grafting $(\mathrm{CABG})$ because of its clear superiority to saphenous vein with respect to long-term patency rate. ${ }^{1.5}$ The most common technique currently employed to harvest the ITA is electrocautery dissection. Arteries are prone to heat damage and spasm

From the Departments of Medicine and Therapeutics ${ }^{\mathrm{a}}$ and of Surgery, ${ }^{\text {b }}$ University of Leicester, Leicester, United Kingdom.

Supported in part by Valleylab, Inc., Boulder, Colo.

Received for publication June 10, 1994; accepted for publication July 26, 1995.

Address for reprints: H. Thurston, MD, FRCP, Department of Medicine and Therapeutics, Clinical Sciences Building, P.O. Box 65, Leicester LE2 7LX, England, United Kingdom.

Copyright (C) 1996 by Mosby-Year Book, Inc.

$0022-5223 / 96 \$ 5.00+0 \quad \mathbf{1 2 / 1 / 6 8 1 9 7}$ as a result of handling, which may in turn lead to damage of the smooth muscle and the endothelium and may influence the long-term outcome of operation. Intraoperative vasodilators such as papavarine are frequently used to alleviate vascular spasm without apparent damage to the vessel. ${ }^{6}$ Damage to the endothelium is considered important because there is evidence for an important role of the endothelium in modulating smooth muscle contraction by the release of prostacyclin, endothelin, and endothelium-derived relaxing factor. ${ }^{7}$ Endotheliumderived relaxing factor is released basally and when the endothelium is stimulated ${ }^{8-10}$ and is absent when the vessels are traumatized. ${ }^{11}$

An alternative to the currently used technique for the dissection of the ITA may be offered by ultrasonic aspirators that use a magnetostrictive transducer. Tissues with high water content, such as fat, 
are fragmented and aspirated, whereas tissues with high elastin and collagen contents are spared. The small vascular branches are thus precisely identified and divided safely.

The aim of this study was to compare an ultrasonic aspirator (CUSA) with conventional electrocautery in the harvesting of the ITA for CABG. The study was performed in two parts, with the initial pilot study performed before a randomized study was undertaken. The aims of the study were to document possible damage by stimulating the smooth muscle of the ITA as well as observing the ability of the endothelium to release endotheliumderived relaxing factor and to demonstrate that the smooth muscle cell cyclic guanosine monophosphate pathway was intact.

\section{Methods}

The study protocol was approved by the Local Ethical Committee. All subjects gave informed consent.

Description of CUSA. The Valleylab Cavitational U1trasonic Aspirator (Valleylab Inc., Boulder, Colo.) was first produced in 1976 for use in the removal of neurogenic tumors and is now being widely used in general and gynecologic surgery. Mechanical energy is transferred to the cells, creating vacuoles within them. These vacuoles expand and collapse as pressure rises and falls with each cycle, generating force. Tissue damage is confined to an area less than $100 \mu \mathrm{m}$ adjacent to the titanium tip of the handpiece. Different tissues fragment at different rates; because blood vessels have low water and high collagen contents, they are resistant to fragmentation, thus allowing the surgeon to avoid damaging these structures. In addition, the CUSA incorporates a series of CAVI-Pulse modes (CAVI modes) that supply power in on-off bursts, allowing preset rest phases during output and thus affording more precisely controlled tissue removal.

Surgical dissection of the ITA. The left ITA was dissected with a "steak" technique. The entire vascular pedicle was taken down en bloc with approximately 1 to 2 $\mathrm{cm}$ of surrounding tissue on either side. The pedicle was first isolated within two cauterized "rails" and was peeled down from the chest with frequent gentle pushes with the flat (nonoperational) portion of the diathermy blade. At this stage, the perforator arteries were identified and divided with cautery as far away from the ITA as possible and were divided between ligature clips (Auto Suture, Premium Surgiclip S-9.0; US Surgical Corporation, Norwalk, Conn.). The dissection (conventional electrocautery or CUSA) was extended distally to just beyond the bifurcation of the ITA and proximally to the origin of the ITA from the left subclavian artery. The concomitant ITA veins were divided between ligature clips, and the left phrenic nerve was always identified. The end result was a pedicle embedded in a 2 to $3 \mathrm{~cm}$ wide strip of muscle and soft tissue. No pharmacologic vasodilators were used during the dissection or before the division of the ITA. Heparin sulfate was administered just before the standard cannulation of the heart for CABG. The bed of the ITA was then checked and all bleeding points were cauterized, regardless of the instrument used for the initial dissection. The redundant length of ITA was taken for laboratory analysis before the patient began heart-lung bypass.

Pilot study. An initial pilot study was performed with 20 patients (five patients per group). Conventional electrocautery or CUSA with settings of $20 \%, 30 \%$, or $50 \%$ power output was used. In all three CUSA groups, there was a reduction in contractile response. There was a significant reduction in endothelium-dependent relaxation in the CUSA $20 \%$ and $30 \%$ groups, but the CUSA $50 \%$ group showed a relaxation response similar to that of the conventional electrocautery group. Endothelium-independent relaxation was found to be similar in all groups.

These results suggest that damage to the vessels dissected with the CUSA at the lower settings was mechanical, rather than ultrasonic. In the randomized study, CUSA settings greater than $50 \%$ were used to minimize this effect.

Randomized study. Sixty patients undergoing elective $\mathrm{CABG}$ with the grafting of a single ITA to the left anterior descending coronary artery were randomly assigned by means of a random number table to one of six groups. These groups (10 patients per group) were conventional electrocautery (control) and CUSA with settings of $60 \%$, $80 \%$, and $100 \%$ power output, $100 \%$ CAVI mode $1(80 \%$ on-off duty cycle), and $100 \%$ CAVI mode 3 (67\% on-off duty cycle). The operations were performed by one surgeon and samples were assayed in a blinded manner; the laboratory worker who completed the assay did not know to which group the patient belonged and the surgeon in the theater was not informed regarding the setting of the CUSA.

Segments of ITA not needed for CABG were obtained and transported to the laboratory in cold $\left(4^{\circ} \mathrm{C}\right)$ calcium-free physiologic salt solution (PSS). The segments were cleansed of connective tissue and cut into two $3 \mathrm{~mm}$ rings by means of a double-bladed scalpel. The exact cutting distance of the two blades was measured with vernier calipers.

The arterial ring was mounted on two stainless-steel hooks (diameter $450 \mu \mathrm{m}$ ). The upper hook was attached to a force transducer to measure isometric tension. The lower hook was fixed to a polymethyl methacrylate plate and connected to a micrometer, which allowed the distance between the two hooks to be adjusted and measured. This apparatus was suspended in a $50 \mathrm{ml}$ organ bath containing PSS. PSS composition was as follows: sodium chloride, $118 \mathrm{mmol} / \mathrm{L}$; potassium chloride, 4.5 $\mathrm{mmol} / \mathrm{L}$; calcium chloride, $2.5 \mathrm{mmol} / \mathrm{L}$; magnesium sulfate $\left(\mathrm{MgSO}_{4} \cdot 7 \mathrm{H}_{2} \mathrm{O}\right), 1 \mathrm{mmol} / \mathrm{L} ;$ potassium phosphate, 1 $\mathrm{mmol} / \mathrm{L}$; sodium carbonate, $25 \mathrm{mmol} / \mathrm{L}$; and glucose, 6 $\mathrm{mmol} / \mathrm{L}$ ). Baths were maintained at $37^{\circ} \mathrm{C}$ and gassed with $95 \%$ oxygen and $5 \%$ carbon dioxide to achieve a $\mathrm{pH}$ of 7.4. ${ }^{12,13}$ Two organ baths were run concurrently, and the results obtained were averaged.

The vessels were allowed to equilibrate for 45 minutes before the length and tension characteristics were determined. The internal diameter was set to $0.9 \times \mathrm{L}_{100}$, where $L_{100}$ is the calculated internal diameter the relaxed vessel would have had in vivo under a transmural pressure of 100 $\mathrm{mm} \mathrm{Hg}(13.3 \mathrm{kPa}){ }^{14,15}$ After normalization, the vessels 
Table I. Maximal responses and sensitivity to vasoconstrictor and vasodilator agents

\begin{tabular}{|c|c|c|c|c|c|c|}
\hline & Diathermy & CUSA $60 \%$ & CUSA $80 \%$ & CUSA $100 \%$ & $\begin{array}{l}\text { CUSA } 100 \% \\
\text { CAVI mode } 1\end{array}$ & $\begin{array}{l}\text { CUSA } 100 \% \\
\text { CAVI mode } 3\end{array}$ \\
\hline \multicolumn{7}{|l|}{ Contraction } \\
\hline KPSS $(\mathrm{mN} / \mathrm{mm})$ & $0.60 \pm 0.26$ & $1.14 \pm 0.17$ & $1.49 \pm 0.60$ & $1.55 \pm 0.36$ & $1.16 \pm 0.27$ & $1.49 \pm 0.58$ \\
\hline $\mathrm{NaK}(\mathrm{mN} / \mathrm{mm})$ & $0.66 \pm 0.38$ & $1.55 \pm 0.25$ & $1.68 \pm 0.82$ & $1.74 \pm 0.47$ & $1.78 \div 0.35$ & $2.28 \pm 1.16$ \\
\hline Noradrenaline $(\mathrm{mN} / \mathrm{mm})$ & $1.30 \pm 0.44$ & $1.78 \pm 0.25$ & $1.52 \pm 0.48$ & $1.76 \pm 0.36$ & $1.66 \pm 0.29$ & $1.75 \pm 0.63$ \\
\hline $\mathrm{ED}_{50}(\mu \mathrm{mol} / \mathrm{L})$ & $0.809 \pm 0.26$ & $1.208 \pm 0.21$ & $1.460 \pm 0.57$ & $1.280 \pm 0.43$ & $1.830 \pm 1.10$ & $1.280 \pm 0.43$ \\
\hline \multicolumn{7}{|l|}{ Relaxation } \\
\hline Acetylcholine $(\%)$ & $49 \pm 15$ & $33 \pm 14$ & $46 \pm 14$ & $43 \pm 10$ & $58 \pm 8$ & $39 \pm 13$ \\
\hline $\mathrm{ED}_{50}(\mu \mathrm{mol} / \mathrm{L})$ & $1.490 \pm 1.30$ & $0.144 \pm 0.08$ & $0.212 \pm 0.08$ & $0.0414 \pm 0.18$ & $0.218 \pm 0.06$ & $0.259 \pm 0.14$ \\
\hline Bradykinin (\%) & $30 \pm 8$ & $22 \pm 8$ & $32 \pm 8$ & $39 \pm 9$ & $29 \pm 7$ & $36 \pm 7$ \\
\hline $\mathrm{ED}_{50}(\mu \mathrm{mol} / \mathrm{L})$ & $0.195 \pm 0.15$ & $0.029 \pm 0.02$ & $0.035 \pm 0.01$ & $0.087 \pm 0.07$ & $0.117 \pm 0.08$ & $0.051 \pm 0.02$ \\
\hline Sodium nitroprusside (\%) & $100 \pm 0$ & $98 \pm 2$ & $96 \pm 2$ & $94 \pm 3$ & $92 \pm 3$ & $96 \pm 3$ \\
\hline $\mathrm{ED}_{50}(\mu \mathrm{mol} / \mathrm{L})$ & $0.209 \pm 0.08$ & $0.210 \pm 0.07$ & $0.428 \pm 0.19$ & $0.254 \pm 0.12$ & $0.321 \pm 0.12$ & $0.135 \pm 0.06$ \\
\hline
\end{tabular}

$\mathrm{NaK}$, KPSS containing noradrenaline $\left(10^{5} \mathrm{~mol} / \mathrm{L}\right) ; E D_{50}$ median effective dose.

were allowed to equilibrate for a further 45 minutes before being stimulated with high-potassium (123 $\mathrm{mmol} / \mathrm{L}$ ) PSS (KPSS) and KPSS containing noradrenaline $\left(10^{-5} \mathrm{~mol} / \mathrm{L}\right)$. KPSS was created by substituting potassium chloride for sodium chloride in equimolar quantities. After membrane depolarization and subsequent contraction, the vessels were rinsed several times with fresh PSS and allowed to return to baseline. A cumulative noradrenaline dose-contraction curve $\left(10^{-8} \mathrm{~mol} / \mathrm{L}\right.$ to $3 \times 10^{-5}$ $\mathrm{mol} / \mathrm{L})$ was obtained in the presence of cocaine $\left(10^{-6}\right.$ $\mathrm{mol} / \mathrm{L}$ ), and after further rinsing and a 20 -minute interval the vessels were submaximally contracted with noradrenaline. When they reached a plateau, the vessels were exposed to cumulative doses of acetylcholine $\left(10^{-8} \mathrm{~mol} / \mathrm{L}\right.$ to $10^{-5} \mathrm{~mol} / \mathrm{L}$ ) and the relaxation response was observed. After a further 20 -minute rest period, this procedure was repeated with bradykinin $\left(10^{-9} \mathrm{~mol} / \mathrm{L}\right.$ to $\left.10^{-6} \mathrm{~mol} / \mathrm{L}\right)$ and then with sodium nitroprusside $\left(10^{-9} \mathrm{~mol} / \mathrm{L}\right.$ to $10^{-5}$ $\mathrm{mol} / \mathrm{L}$ ).

Drugs. Cocaine hydrochloride, noradrenaline, acetylcholine hydrochloride, bradykinin, and sodium nitroprusside were obtained from Sigma Chemical Company (St. Louis, Mo.), dissolved in distilled water, and diluted with PSS. All drug concentrations are expressed as final molar concentration in the organ bath.

Expression of results. The responses for each patient were averaged, and tension was expressed in millinewtons per millimeter of vessel length. Relaxation responses were expressed as the percentage reduction in the noradrenaline-induced contraction. Results are reported as mean values ( \pm standard error of the mean). The normal distribution is generally accepted for log dose-response curves, ${ }^{16}$ so parametric statistics are applicable provided homogeneity of samples can also be assumed. Homogeneity can be assumed if the ages of the patients and the in vivo sites of the samples are similar. ${ }^{17}$ Significant differences were determined with an unpaired Student's $t$ test with Dunnet correction for multiple comparisons, and the dose-response curves were analyzed with analysis of variance, accepting $p<0.05$ as significant.

\section{Results}

Sixty samples, from 10 patients in each group were obtained. Patient characteristics were as follows: 51 men, 9 women; age 34 to 77 years (mean $59.25 \pm 1.2$ years); mean blood pressure range 73 to $133 \mathrm{~mm} \mathrm{Hg}$ (mean $101.0 \pm 1.5 \mathrm{~mm} \mathrm{Hg}$ ); there were no significant differences among the groups. There were no differences among groups with respect to the drug therapy that the patients were receiving. All patients were taking nitrates and 47 were taking calcium antagonists, 39 were taking $\beta$-blockers, and 36 were receiving aspirin therapy. Seventeen patients were taking diuretics and 15 patients were taking angiotensin-converting enzyme inhibitors. One patient had insulin-dependent diabetes (CUSA $60 \%$ group) and two patients had non-insulin dependent diabetes (CUSA $60 \%$ and CUSA $100 \%$ CAVI mode 1 groups). Each group contained at least one patient receiving lipid-lowering therapy except for the CUSA $80 \%$ group, which had two patients receiving this therapy.

The internal vessel diameters from the six groups were similar. The average internal diameter in the control group was $2280 \pm 112 \mu \mathrm{m}$; in the CUSA $60 \%, 80 \%, 100 \%, 100 \%$ CAVI mode 1 , and $100 \%$ CAVI mode 3 groups, means were $2215 \pm 118 \mu \mathrm{m}$, $2231 \pm 114 \mu \mathrm{m}, 2353 \pm 102 \mu \mathrm{m}, 2265 \pm 83 \mu \mathrm{m}$, and $2101 \pm 145 \mu \mathrm{m}$, respectively. Stimulation with KPSS produced similar contractions in all the groups. In the control group, however, eight vessels from four of the 10 patients did not respond, and the mean response was $0.60 \pm 0.26 \mathrm{mN} / \mathrm{mm}$. Two vessels from one patient in each of the CUSA $60 \%, 80 \%$, and $100 \%$ groups failed to respond to potassium, and 
the mean responses were $1.14 \pm 0.17 \mathrm{mN} / \mathrm{mm}, 1.49$ $\pm 0.60 \mathrm{mN} / \mathrm{mm}$, and $1.55 \pm 0.36 \mathrm{mN} / \mathrm{mm}$, respectively. In the CUSA $100 \%$ CAVI mode 1 group, all vessels responded to potassium, and the mean response was $1.16 \pm 0.27 \mathrm{mN} / \mathrm{mm}$. In the CUSA $100 \%$ CAVI mode 3 , group four vessels from two patients failed to respond to potassium, and the mean response was $1.49 \pm 0.58 \mathrm{mN} / \mathrm{mm}$ (Table I).

KPSS containing noradrenaline $\left(10^{-5} \mathrm{~mol} / \mathrm{L}\right)$ produced similar contractions in the CUSA groups as in the control preparation (Table I). Only the vessels in the CUSA 100\% CAVI mode 1 group showed a significant improvement versus diathermy with respect to occurrence of response $\left(p<0.05, \chi^{2}\right.$, Fisher's exact test). Vessels that failed to respond to KPSS with and without noradrenaline also failed to contract in response to increasing concentrations of noradrenaline. In the control group, $60 \%$ of the vessels responded, with a maximum contraction of $1.30 \pm 0.44 \mathrm{mN} / \mathrm{mm}$. In the CUSA $60 \%, 80 \%$, and $100 \%$ groups, $90 \%$ of the vessels responded to noradrenaline, with maximum contractions of $1.78 \pm 0.25 \mathrm{mN} / \mathrm{mm}, 1.52 \pm 0.48 \mathrm{mN} / \mathrm{mm}$, and $1.76 \pm 0.36 \mathrm{mN} / \mathrm{mm}$, respectively. In the CUSA $100 \%$ CAVI mode 1 group, $100 \%$ of the vessels responded to noradrenaline, with a maximum response of $1.66 \pm 0.29 \mathrm{mN} / \mathrm{mm}$. In the CUSA $100 \%$ CAVI mode 3 group, $80 \%$ of the vessels responded to noradrenaline, with a maximum response of 1.75 $\pm 0.63 \mathrm{mN} / \mathrm{mm}$ (Table I). There were no changes in sensitivity to noradrenaline compared with control, as shown by the concentration producing $50 \%$ of the maximum contraction (Table I).

Vessels that failed to contract to KPSS or noradrenaline were excluded from the relaxation studies. Acetylcholine produced similar concentrationdependent relaxations in all groups, and the maximum relaxations to acetylcholine were $49 \pm$ $15 \%$ in the control group, $33 \pm 14 \%$ in the CUSA $60 \%$ group, $46 \pm 14 \%$ in the CUSA $80 \%$ group, 43 $\pm 10 \%$ in the CUSA $100 \%$ group, $58 \pm 8 \%$ in the CUSA $100 \%$ CAVI mode 1 group, and $39 \pm 13 \%$ in the CUSA $100 \%$ CAVI mode 3 group (Table I). Bradykinin produced similar concentration-dependent relaxations in the control, CUSA $60 \%$, and CUSA $80 \%$ groups. In the three remaining CUSA groups, there was no significant difference in the maximum response to bradykinin but there were significant improvements in relaxation when the whole line was analyzed with analysis of variance $(p$ $<0.05$ ) (Table I, Fig. 1). Sodium nitroprusside produced complete relaxation in all groups (control,

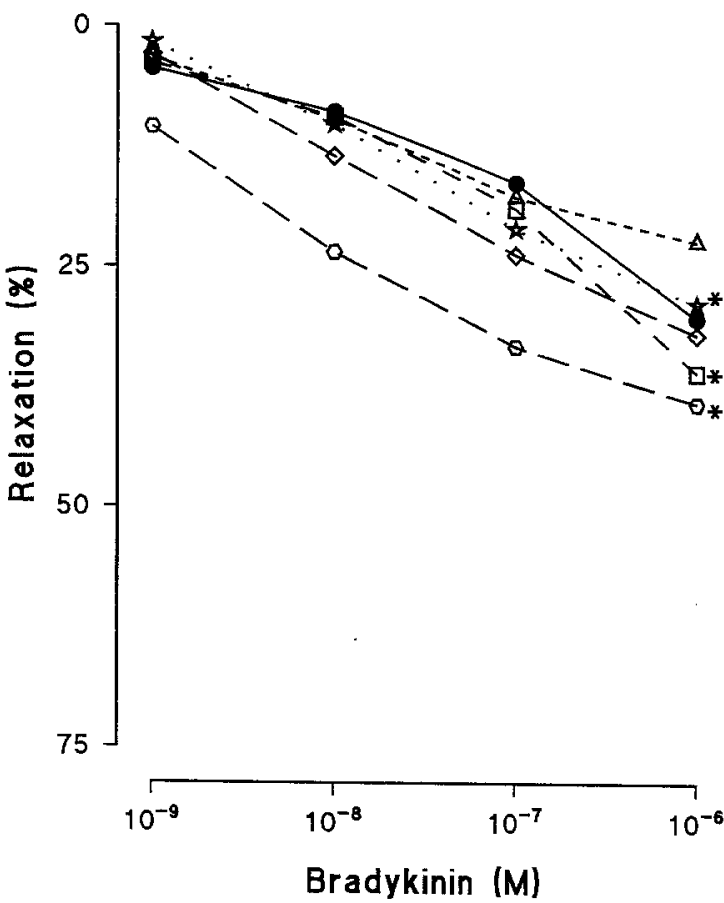

Fig. 1. Shows the relaxation response to bradykinin in the control $(\bigcirc)$, CUSA $60 \%(\triangle)$, CUSA $80 \%(\diamond)$, CUSA $100 \%(\bigcirc)$, CUSA $100 \%$ CAVI mode $1($ 㳄), and CUSA $100 \%$ CAVI mode $3(\square)$. Asterisk represents $p<0.05$.

$100 \pm 0 \%$; CUSA $60 \%, 98 \pm 2 \%$; CUSA $80 \%, 96 \pm$ $2 \%$; CUSA $100 \%, 94 \pm 3 \%$; CUSA $100 \%$ CAVI mode 1, $92 \pm 3 \%$; and CUSA $100 \%$ CAVI mode 3 , $96 \pm 3 \%$; Fig. 2). There was no change in sensitivities to acetylcholine, bradykinin, or sodium nitroprusside compared with control, as shown by the concentrations producing $50 \%$ of the maximum contraction (Table I).

\section{Discussion}

Use of CUSA in the dissection of the ITA for CABG was first reported by Suma, Fukumoto, and Takeuchi ${ }^{18}$ in 1987. They found that the instrument shortened dissection time and reduced the amount of bleeding when compared with conventional electrocautery. It is difficult to compare methods of dissection in a quantitative manner, and we did not evaluate dissection time and bleeding. It was apparent, however, that visualization of the branches of the ITA with CUSA was particularly rewarding in the proximal area, which is often surrounded by a considerable amount of fatty tissue obscuring the origin of the internal thoracic vein and the anatomy of the phrenic nerve. The disadvantage of the 


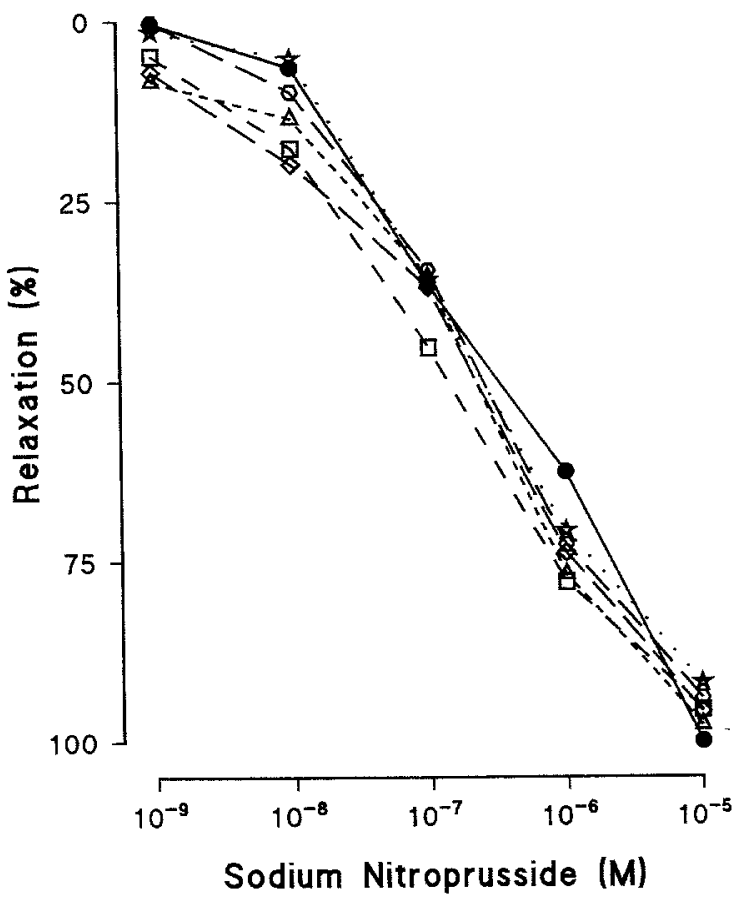

Fig. 2. Shows the relaxation response to sodium nitroprusside in the control $(\bigcirc)$, CUSA $60 \%(\triangle)$, CUSA $80 \%$ $(\diamond)$, CUSA $100 \%(\bigcirc)$, CUSA $100 \%$ CAVI mode 1 ( and CUSA $100 \%$ CAVI mode $3(\square)$.

method was the presence of an extra instrument on the operating table, which for some surgeons may offset any advantages of the instrument. We have been cautious in introducing the ultrasonic aspirator into routine operations mainly because of the concern that the instrument could cause damage to the endothelium and to the smooth muscle, which would affect vascular tone. Recent publications on the subject of spasm in the ITA suggest that spasm is most likely caused by handling of the artery during its dissection. ${ }^{19}$

Damage to the ITA is of concern because of the risk of perioperative spasm in the early postoperative recovery period, which may lead to acute ischemia and influence both the outcome of the operation and early and late patency changes. Damage to the smooth muscle affects vascular tone, and damage to the endothelium results in loss of production of vasoactive substances that regulate smooth muscle contractility and platelet aggregation. When CUSA began to be used, it rapidly became apparent that the higher outputs of the ultrasonic aspirator resulted in a better quality of dissection. Concern was raised, however, that such outputs might possibly enhance damage to the artery.

The results from the randomized study show that conventional electrocautery caused $40 \%$ damage or trauma to the ITA, four of the CUSA settings caused $20 \%$ damage or trauma, and a CUSA setting of $100 \%$ CAVI mode 1 caused no apparent damage or trauma to the arteries. There was no reduced contractility in the CUSA experimental groups versus the control vessels, whether by membrane depolarization or by receptor-mediated means. With respect to the overall response to the receptorinduced and non-receptor induced contractility, the CUSA samples performed better than those harvested with conventional electrocautery, with the three $100 \%$ CUSA groups producing the greatest overall contraction.

Vessels that failed to contract had to be excluded from relaxation studies. In the remaining vessels, endothelium-dependent relaxation induced by the vasodilator acetylcholine was similar in all the CUSA groups when compared with control values. When bradykinin was used as a vasodilator, however, there was significant improvement in the relaxation with the $100 \%, 100 \%$ CAVI mode 1 , and $100 \%$ CAVI mode 3 CUSA power outputs. This result suggests that there was less damage or trauma at these three power settings, rather than more as had been feared. The results of the endotheliumindependent vasodilator sodium nitroprusside showed that there was no difference between the CUSA groups and control. All the vessels relaxed fully, indicating that the cyclic guanosine monophosphate pathway was functioning normally.

\section{Conclusion}

Our results suggest that the CUSA settings $100 \%$ and $100 \%$ CAVI mode 1 result in reduced damage and trauma during harvesting of the ITA compared with conventional electrocautery. This result, in combination with the ease of CUSA dissection, may improve outcomes of CABG. In addition, CUSA may prove to be an effective teaching tool for less-experienced surgeons.

We thank the operating theater staff at Groby Road Hospital for their help in this study.

\section{REFERENCES}

1. Grondin CM, Campeau L, Lesperance J. Comparison of late change in internal mammary artery and saphenous vein grafts in ten consecutive series of patients, ten years after operation. Circulation 1984;70(Suppl 1):208-21.

2. Okies JE, Page US, Bigelow JC, Krause AH, Solomon MW. The left internal mammary artery the graft of choice. Circulation 1984;70(Suppl 1):213-21. 
3. Lytle BW, Loop FD, Cosgrave DM. Long term (5-12 years) study of internal mammary artery and saphenous vein coronary bypass grafts. J Thorac Cardiovasc Surg 1985;89:248-58.

4. Angelini GD, Bryan AJ, West RR, Newby AC, Breckenbridge IM. Coronary artery bypass surgery: current practice in the United Kingdom. Thorax 1989;44:721-4.

5. Cameron EW, Walker WS. Coronary artery bypass surgery: choice of conduit influences outcome. BMJ 1990;300:1219-20.

6. Hillier C, Watt PA, Spyt TJ, Thurston H. Contraction and relaxation of human internal mammary artery after intraluminal administration of papaverine. Ann Thorac Surg 1992; 53:1033-7.

7. Furchgott RF, Zawadzki JV. The obligatory role of endothelial cells in relaxation of arterial smooth muscle by acetylcholine. Nature 1980;299:373-6.

8. Ignarro LJ. Biological actions and properties of endotheliumderived nitric oxide formed and released from artery and vein. Circ Res 1989;65:1-22.

9. Vallance P, Collier J, Moncada S. Effects of endotheliumderived nitric oxide on peripheral arteriolar tone in man. Lancet 1989;2:997-1000.

10. Dainty IA, McGrath JC, Spedding M, Templeton AG. The influence of the initial stretch and the agonist-induced tone on the effect of basal and stimulated release of EDRF. Br J Pharmacol 1990;100:767-73.

11. Sayers RD, Watt PA, Muller S, Bell PR, Thurston H. Endothelial cell injury secondary to surgical preparation of reversed and in-situ saphenous vein bypass grafts. Eur J Vasc Surg 1992;6:354-61.

12. Gui-We H, Angus JA, Rosenfeldt FL. Reactivity of the canine isolated internal mammary artery, saphenous vein and coronary artery to constrictor and dilator substances: relevance to coronary bypass graft surgery. J Cardiovasc Pharmacol 1987;12:12-22.

13. Mulvany MJ, Halpern W. Mechanical properties of vascular smooth muscle cells in situ. Nature 1976;260:617-9.

14. Angus JA, Cocks TM, Satoh K. $\alpha$-Adrenoceptors and endothelium-dependent relaxation in canine large arteries. $\mathrm{Br} \mathbf{J}$ Pharmacol 1986;88:767-77.

15. Mulvany MJ, Halpern W. Contractile properties of small arterial resistance vessels in spontaneously hypertensive and normotensive rats. Circ Res 1977;41:19-26.

16. Goldstein A. Biostatistics: an introductory text. New York: Macmillan, 1964.

17. Altura BM, Altura BT. Heterogeneity of drug receptors in different segments of rabbit thoracic aorta. Eur J Pharmacol 1970;12:44-52.

18. Suma H, Fukumoto H, Takeuchi A. Application of ultrasonic aspirator for dissection of the internal mammary artery in coronary artery bypass grafting. Ann Thorac Surg 1987;43: 676-7.

19. Massa G, Johansson S, Kimbald P-O, et al. Might free arterial grafts fail due to spasm? Ann Thorac Surg 1991;51: 94-101. 